\title{
Gestação de substituição transfronteiriça à luz da jurisprudência do TEDH: algumas reflexões
}

https://doi.org/10.21814/uminho.ed.30.10

\author{
Diana Coutinho \\ Assistente Convidada da EDUM
}

\section{Enquadramento}

Nas últimas décadas assistimos ao crescimento exponencial da prática de gestação de substituição transfronteiriça ${ }^{1}$. Esta prática caracteriza-se pela deslocação de casais ou pessoas sozinhas do seu país de origem para um país que permite a celebração de contratos de gestação de substituição, inclusive a título oneroso, com o único intuito de ter um filho com recurso a uma gestante de substituição. A diferença entre as legislações internas dos Estados, a ausência de um instrumento internacional que possa servir de critério uniformizador, a facilidade de deslocação entre países ou a ânsia desenfreada pelo desejo de ter um filho, entre outras razões, tornaram a gestação de substituição transfronteiriça uma das práticas mais procuradas de turismo reprodutivo.

São várias as questões jurídicas de Direito Internacional Privado em torno da gestação de substituição internacional. Face à dimensão do presente estudo apenas vamos abordar algumas questões em torno do estabelecimento e reconhecimento da filiação no âmbito de contratos de gestação de substituição transfronteiriços. É neste contexto que o Tribunal Europeu dos Direitos Humanos (TEDH) tem proferindo algumas decisões, em particular à luz do direito ao respeito pela vida privada e familiar (art. 8. ${ }^{\circ}$ da Convenção Europeia dos Direitos do Homem). Pretendemos apresentar algumas reflexões sobre os principais contributos do TEDH, com o intuito de perceber se a sua posição tem promovido uma mudança de paradigma nesta matéria.

\section{Decisões judiciais}

As decisões do TEDH sobre gestação de substituição internacional podem ser agrupadas em quatro grupos em virtude da similitude factual e jurídica².

10 presente artigo tem por base a nossa tese de Doutoramento em Ciências Jurídicas-Privatísticas subordinada ao tema "As problemáticas e desafios contemporâneos em torno da Gestação de Substituição", entregue em fevereiro de 2021 e com provas públicas agendadas para 23 julho de 2021.

2 A dimensão do presente artigo não nos permite desenvolver a matéria factual e jurídica dos casos judiciais do TEDH. Todas as decisões estão disponíveis para consulta no site oficial do TEDH. [Consultado em 03.05.2021]. Disponível na WWW: < https://www.echr.coe.int/Pages/home.aspx?p=home>. 
As decisões judiciais que integram o primeiro grupo referem-se a situações de recusa de transcrição de certidões de nascimento emitidas por autoridades estrangeiras, na sequência da celebração de contratos internacionais de gestação de substituição. Neste grupo de decisões, o TEDH discutiu o respeito pela vida privada e familiar dos beneficiários e das crianças, confrontando a liberdade dos Estados em legislar sobre esta matéria e intervenção da reserva de ordem pública internacional (ROPI) com a proteção do superior interesse da criança. Deste grupo fazem parte o caso Mennesson contra França (2014); o caso Labassee contra França (2014); o caso Foulon e Bouvet contra França (2016) e o caso Laborie contra França (2017), os casos C e caso E contra França (2019) e o caso D contra França (2020).

O segundo grupo de decisões do TEDH tem como base comum a recusa da emissão de documentos de viagens por parte das autoridades do país de origem dos beneficiários de um contrato de gestação de substituição, ou seja, nas dificuldades enfrentadas pelos beneficiários para sair do país de nascimento da criança. Neste grupo destacamos o caso $D$ and Others contra Bélgica (2014).

No terceiro grupo de decisões encontramos o caso Paradiso et Campanelli contra Itália (2015 e 2017), um dos casos mais polémicos em matéria de gestação de substituição transfronteiriça, com duas decisões distintas do TEDH sobre o reconhecimento da filiação constituída no estrageiro quando não existe laço genético entre a criança e os beneficiários. 0 conceito de vida privada e familiar foi novamente chamado a debate, bem como a reserva de ordem pública internacional.

No último e quarto grupo, destacamos o caso Lanzmann contra França (2019), que trouxe à discussão do TEDH a questão da gestação de substituição post mortem, o direito à reprodução e o "direito" a ser avó.

\section{Principais contributos do TEDH}

A pronúncia do TEDH sobre questões em torno da prática da gestação de substituição internacional tem tido como foco a proteção dos interesses da criança nascida na sequência de um contrato de gestação de substituição transfronteiriço, sobretudo quanto ao seu direito à identidade e à vida privada familiar.

O TEDH ainda não se pronunciou sobre a admissibilidade ou proibição desta prática, uma vez que entende que os Estados têm liberdade para regulamentar essa matéria, embora considere que a diversidade de regulamentação não pode ser um fator de tratamento discriminatório e de desproteção do superior interesse da criança. Assim, o TEDH reconhece que este é um tema sobre o qual não há consenso e, por conseguinte, confere aos Estados uma ampla mais de apreciação para legislar sobre esta matéria. Além disso, o TEDH considera que não tem competência para se substituir às autoridades nacionais na definição das suas políticas legislativas ${ }^{3}$. Desta forma,

3 Por exemplo, v. o ponto 78 da decisão Mennesson contra França ou ponto 37 da decisão Labassee contra França. 
continuamos a desconhecer qual a posição do TEDH sobre questões importantes em torno desta prática, por exemplo, sobre a onerosidade destes contratos, o perigo e risco de venda de crianças, as consequências em caso de incumprimento contratual, a exploração da gestante, o exercício do direito ao arrependimento, o respeito pela dignidade humana da gestante e da criança4 ${ }^{4}$, entre tantas outras questões.

Apesar da liberdade dos Estados em fixar as regras quanto à admissibilidade ou proibição da gestação de substituição, o TEDH entende que a proibição da prática de gestação de substituição num determinado país não pode ser motivo idóneo para justificar o não reconhecimento do contrato validamente celebrado em país que o admita, em especial quanto aos efeitos da filiação. Por outras palavras, esta liberdade não permite aos Estados rejeitar o reconhecimento da filiação legalmente estabelecida no estrangeiro, em virtude da tutela do superior interesse da criança nascida na sequência de um contrato de gestação (em particular, do seu direito ao respeito pela vida privada na vertente de identidade pessoal, consagrado no art. $8 .^{\circ} \mathrm{da}(\mathrm{CDH})$.

Nos primeiros casos judiciais apreciados pelo TEDH, este tribunal começou apenas por dar relevância à ligação genética estabelecida entre o beneficiário-pai intencional e a criança ${ }^{5}$, considerando que, sempre que exista esta ligação, deve ser reconhecida a filiação constituída legalmente no estrangeiro, pois a realização do direito à identidade da criança passa por ver reconhecidos os laços de filiação com quem se tem ligação genética.

Esta posição foi também manifestada no parecer consultivo emitido pelo TEDH em 20196,7. Em síntese, o TEDH entendeu, por unanimidade, que devem ser adotadas pelos Estados algumas orientações sobre o reconhecimento da filiação da criança nascida no estrangeiro na sequência de um contrato internacional de gestação de substituição, quando a criança foi concebida com gâmetas do beneficiário e óvulos doados e cuja relação de paternidade foi reconhecida no direito interno: (i) o direito da criança à vida privada nos termos do art. $8 .^{\circ}$ da CEDH impõe a obrigação aos Estados de reconhecerem a maternidade validamente constituída no estrangeiro em relação à mulher (tenha ou não contribuído com os óvulos) que consta na certidão de registo de nascimento como sendo a mãe legal; (ii) este direito não impõe a obrigação do reconhecimento se operar por via de registo do nascimento; os Estados têm liberdade de adotar um outro meio - como a adoção -, desde que seja um meio

4 Nas declarações de voto do caso Paradiso e Campanelli (2017), os juízes manifestaram a sua posição quanto à violação da dignidade humana decorrente da prática de gestação de substituição, independentemente da modalidade praticada, bem como consideraram que os contratos onerosos configuravam venda de crianças. Além disso, os Juízes consideraram que a decisão foi omissão na pronúncia sobre o tráfico de seres humanos e a referência aos instrumentos internacionais que regulam essa matéria, omissão que não deveria ter acontecido. Salientaram também a importância da ligação uterina e do parto e o direito da gestante se arrepender.

5 Nas decisões judiciais do primeiro grupo.

6 Na sequência de um pedido apresentado pela Estado francês relativo ao caso Mennesson contra França.

7 Em todos os casos (exceto o Paradiso e Campanelli) a criança tinha ligação genética com o beneficiário. 
adequado, célere e efetivo, de acordo com o superior interesse da criança. Desta forma, o TEDH reconheceu o direito da criança ver reconhecida a filiação que foi legalmente estabelecida no estrangeiro, mesmo que só tenha ligação genética com o beneficiário-pai, o que é fundamental para garantir o seu bem-estar e o seu superior interesse, já que, sem tal reconhecimento, podem surgir inúmeras dificuldades de ordem prática que colocam a criança numa situação de insegurança jurídicå.

Conforme referimos supra, esta orientação do TEDH não obriga os Estados a transcrever para o seu registo civil a certidão de nascimento estrangeiro ou a reconhecer os efeitos da sentença estrangeira quanto à relação jurídica de maternidade, tão-só a proporcionar os meios para que tal reconhecimento seja efetivado. É uma solução que se assume como intermédia. Por um lado, pretenda acautelar os interesses da criança, reconhecendo a relação validamente constituída no estrangeiro, e, por outro lado, permite aos Estados (incluindo os que proíbem a prática no seu território) um controlo através da fixação dos meios para esse reconhecimento. Pode não constituir a solução ideal, mas consideramos que procura conciliar os interesses dos envolvidos, não deve ser vista como discriminatória em função do género, mas interpretada à luz dos critérios de estabelecimento da maternidade adotado pela generalidade dos Estados que justificam procedimentos adicionais para o reconhecimento 9 .

Neste contexto, referia-se que o TEDH ainda não se pronunciou sobre se o reconhecimento da relação legal de filiação, validamente constituída no estrangeiro, se aplica se o beneficiário (sem ligação genética com a criança) for um homem ${ }^{10}$. Porém, a pronúncia pode estar para breve, uma vez que se encontram pendentes dois processos judiciais (julgados em conjunto), a saber no caso Schlittner-Hay contra Polónia ${ }^{11}$. Neste caso, os beneficiários do contrato de gestação de substituição celebrado nos Estados Unidos da América são um casal de homens, de nacionalidade polaca e polaca-israelense, com residência habitual em Israel. Na sequência do contrato celebrado nasceram duas crianças que adquiriram a nacionalidade norte-americana. O Sr. Schlittner é o pai genético dos gémeos. Por sentença emitida pelo tribunal da Califórnia foi transferida a parentalidade para os beneficiários, com direitos iguais, não reconhecendo qualquer direito à gestante de substituição. $O$ litígio surge na sequência da atuação das autoridades polacas que se recusaram a atribuir a nacionalidade polaca aos gémeos, embora tivessem ligação genética com um nacional polaco (o Sr. Schlittner). As autoridades polacas também se recusaram a transcrever a certidão de nascimento norte-americana por constar o nome dos dois homens como

8 Por exemplo, dificuldades de obtenção da nacionalidade do país de origem da beneficiária, da permanência no país de residência habitual, direitos sucessórios, assunção das responsabilidades parentais, o destino da criança em caso de morte do progenitor masculino, entre outros.

9 A nosso ver o procedimento de reconhecimento deverá impor um comprovativo da prestação válida do consentimento da gestante, ou seja, deve comprovar-se que a gestante não se arrependeu e aceitou voluntaria e livremente entregar a criança aos beneficiários.

10 Ou um casal de mulheres ou uma mulher sozinha, pois em relação ao homem sozinho que for pai genético, parece-nos que valerão as mesmas regras descritas supra.

11 Pedidos n.os 56846/15 e 56849/15. [Consult. 06.01.2021]. Disponível em WWW: $<$ http://media.aclj. org/pdf/Schlittner-Hay-v-Poland,-Written-Observations,-ECL,-July-2019.pdf >. 
pais. Face ao exposto, o casal acusou as autoridades polacas de um comportamento discriminatório em razão da homossexualidade dos pais.

As decisões do TEDH têm afirmando também que a reserva de ordem pública internacional (ROPI), mecanismo excecional e exclusivo do Estado do foro, não pode ser usada constantemente como fundamento da recusa de reconhecimento de sentenças estrangeiras ou da transcrição de atos de registo civil lavrados no estrangeiro, quando da sua aplicação resulte a desproteção do superior interesse da criança. Em particular, o TEDH destaca a necessidade de proteção do direito ao respeito pela vida privada e também o respeito pela vida familiar dos beneficiários de um contrato de GS e da própria criança. Embora o TEDH reconheça a complexidade da matéria e as diferenças (legítimas) na regulamentação interna dos Estados em matéria de gestação de substituição ${ }^{12}$. Assim, embora a ROPI permita aos Estados recusarem os efeitos da filiação constituída no estrangeiro quando tal reconhecimento afete princípios fundamentais da ordem jurídica do foro, inclusivamente pela margem de apreciação que é conferida para a ingerência na vida privada e familiar, nos termos do art. $8 .^{\circ}$, n. $^{\circ} 2$ da CEDH (em ponderação de interesses públicos), o TEDH tem entendido que a ROPI não pode atuar se estiverem verificadas três condições (i) o reconhecimento da filiação legal do progenitor geneticamente relacionado com a criança; (ii) a filiação legal tenha sido validamente estabelecida no país de nascimento; (iii) não exista qualquer alternativa através da qual a relação legal entre os beneficiários e a criança possa ser legalmente estabelecida no Estado de destino. Assim, este posicionamento do TEDH configura uma importante contribuição para a mudança de paradigma no tratamento das relações internacionais de gestação de substituição, em particular em nome dos direitos humanos da criança.

A jurisprudência do TEDH em matéria de gestação de substituição contribuiu para reforçar o conceito de vida privada e familiar do art. $8 .^{\circ}$ da CEDH. Desta jurisprudência resulta o reconhecimento que as famílias contemporâneas não são mais estáticas e fixadas num Estado, há problemas transfronteiriços, que impõem o reconhecimento das relações familiares para além das fronteiras de um Estado. Por conseguinte, 0 carácter de estraneidade das relações humanas familiares impõe uma interpretação dinâmica do conceito de vida privada e familiar do art. 8. ${ }^{\circ}$ da CEDH, a análise casuística do caso concreto e a primazia pelo superior interesse da criança. Das decisões descritas supra, em particular do caso Paradiso e Campanelli, resulta que a imposição do reconhecimento da filiação não decorre do direito ao respeito pela vida familiar, mas do direito ao respeito pela vida privada da criança. No conteúdo do direito à vida privada da criança, inclui-se o direito à identidade e considera-se que existe um nexo entre o direito à vida privada das crianças e a determinação jurídica da sua filiação. Desta forma, para que haja respeito pelo direito à vida privada exige-se que todas as pessoas tenham direito à sua identidade, o que inclui o direito à filiação devidamente reconhecida.

12 O TEDH reconheceu que os Estados podem ter motivos legítimos para a recusa - desincentivar o turismo reprodutivo, proibir a prática por motivos éticos e evitar que os beneficiários defraudem as leis do seu Estado de origem -, porém esses motivos não podem prejudicar o superior interesse da criança. 
Por último, da jurisprudência do TEDH tem resultado o reconhecimento do direito à reprodução, integrando-o no âmbito do direito ao respeito pela vida privada $\mathrm{e}$ familiar previsto no art. $8 .^{\circ}$ da $\mathrm{CEDH}$, embora da CEDH não resulte um direito à reprodução ou a constituir família com recurso à gestação de substituição, mas apenas se reconhece a existência de famílias já constituídas, mesmo que sejam famílias de facto e independentemente do laço do casamento e da ligação genética. Porém, deste direito à reprodução não contempla o direito à reprodução assistida ou à gestação de substituição post mortem com o propósito de ter um neto.

\section{Síntese conclusiva}

A jurisprudência do TEDH tem constituído um precedente a observar pelos Estados aderentes à Convenção Europeia dos Direitos do Homem. Em suma, as decisões do TEDH têm contribuído para uma mudança de paradigma no tratamento de questões em torno da gestação de substituição transfronteiriça, particularmente quanto ao reconhecimento de efeitos de filiação constituída em país estrangeiro. 0 apelo ao critério do superior interesse da criança - para regular litígios que possam surgir no âmbito desta prática - ganha cada vez mais relevo em detrimento de interesses nacionais dos Estados.

Da jurisprudência do TEDH resulta uma posição diferenciada quanto ao reconhecimento de efeitos à filiação constituída no estrangeiro, consoante os beneficiários tenham ou não ligação genética com a criança, embora a exigência deste reconhecimento resulte sempre do direito ao respeito pela vida privada da criança (em especial, o seu direito à identidade). Desta forma, no caso de um casal heterossexual de beneficiários é suficiente que pelo menos um dos membros tenha ligação genética com a criança para que se possa considerar a prevalência do direito ao respeito pela vida privada da criança (direito à identidade). Este direito foi objetivamente reconhecido em relação ao progenitor genético, embora se ficcione o reconhecimento em relação ao membro do casal que não tem ligação genético, sem prejuízo dos Estados terem uma margem de apreciação para determinar os meios para efetivar este reconhecimento. Pelo contrário, na ausência de ligação genética entre os beneficiários e a criança, os Estados têm uma margem de apreciação para rejeitar o reconhecimento da relação de filiação, inclusive com base na reserva de ordem pública internacional, ressalvando o caso dessa recusa colocar em causa o princípio do superior interesse da criança. Entende-se que o direito à vida privada da criança deve ser apreciado de forma autónoma do direito à sua vida familiar. Neste último caso, apenas deve ser concedida à criança a possibilidade de viver com os beneficiários em condições normais e sem restrições. A ROPI deve ser afastada para favorecimento de uma situação já criada e efetiva, sempre que o não reconhecimento da relação de filiação constituída no estrangeiro implique uma violação do superior interesse da criança. 